\title{
Correlation between Elegance of Parenting and Emotional Intelligence among Chinese Elementary School Students
}

\author{
Dr Muhammad Naveed Jabbar, SEML, Universiti Utara Malaysia. E-mail: m.naveedjabbar@gmail.com \\ Wu Deli, Beibu Gulf University, China \\ *Dr Muhammad Aamir Hashmi, IER, University of the Punjab E-mail: aamirhashmi.ier@pu.edu.pk
}

\begin{abstract}
Parenting styles are psychological constructs representing standard strategies that parents use in their child rearing and emotional intelligence helps the students to act positively for the enhancement of their academic achievements. The main objective of this paper is to determine the correlation between parenting and students' emotional intelligence. The study was based on the quantitative and cross sectional research design. The elementary school students from Guangxi, China were the population of this study whereas, 239 respondents were selected as sample through simple random technique. The data was collected through standardize questionnaire by using survey method. SPSS Ver.25 was administered for descriptive and inferential statistics. The findings of the study revealed that there was a moderate and positive effect of parenting styles on emotional intelligence of the elementary school students. Moreover, Authoritative and permissive styles of parenting have strong positive effect on emotional intelligence than authoritarian. This study is beneficiary for parents and educationists that they have keep in mind the importance of emotional intelligence of students during the curricular and extracurricular activities.
\end{abstract}

Keywords: Parenting, Emotional Intelligence, Elementary School Students

Received: $19.11 .2020 \quad$ Accepted: 16.12 .2020

Published: 10.01 .2021

\section{INTRODUCTION}

Parentig or Child rearing is the process of promoting and supporting the physical, emotional, social and intellectual development of a child from infancy to adulthood. Parenting refers to the intricacies of raising a child and not exclusively for a biological relationship (El-Sheikh et al., 2010; Lekavicienea \& Antinieneb, 2016). Moreover, Parenting practices are the behavioural strategies that parents employ to socialize their children. In the context of learning activity, practices such as emotional support has been shown to be positively associated with emotional intelligence. However, Parenting styles are the representation of how parents respond to and make demands on their children (Ogunleye, Omirin \& Balogun, 2013). Parents play a vital role for the development of the child and being responsible for the good care of the child in early life. On the other hand parenting plays a vital role for adopting the best behavior toward others. It mostly focuses on the social needs of the child (Khajehpour, 2011; Arzeen et al., 2012). The parental style is likely to supervise the whole environment of home and try to eradicate all the problems faced by the children (Chidiebere, 2016). The home environment mainly interact the students. The students act as they have influenced by their parents. Parental style is one of the greatest factors which play a vital role for the behavior development of the students (Alizade et al., 2011). Students learn a lot from their parents rather than among school community (Barnhart et al., 2013). The outcome during school activities is depends upon the best scale of parenting. The students have great influence of parenting for their personality grooming and the parental style based on social norms. (Kordi et al., 2010; Asghari et al., 2011; Nayereh Parishani \& Parisa Nilforoosha, 2014). Parenting has a positive effect on the emotional intelligence of the students especially at elementary level (Lekavicienea \& Antinieneb, 2016). Whereas, Emotional intelligence is the ability of an individual to perform well in crucial situation. In psychological aspects intelligence is the capacity to solve out the problems according to the ability and experience and overcome the feelings and emotions (Caruso, Mayer 
\& Salovey, 2010; Nayereh Parishani \& Parisa Nilforoosha, 2014). There is a strong relationship between parenting and emotional intelligence for the development of their academic career (Khajehpour, 2011; Rivers et al., 2012; Mattar, 2017).

\section{LITERATURE REVIEW}

Parenting styles considered as a nourishment of the children especially at elementary level. Parenting and emotional intelligence have strong relationship between each other. Parenting is a process of promoting dream into reality accept frustration, ability to live relative freedom from tension how to cope in worse situation (Lekavicienea \& Antinieneb, 2016). Previous research has identified authoritative style considers to be most effective style use by most of the parents. It is high warm and high control. Among all the factors included in the parenting styles authoritarian parenting style is an important factor for the control of emotions and feelings of the students (Khajehpour, 2011; Alegre, 2012; Williams, 2013). There are two types of parenting maternal and paternal both the parenting styles deal with the positive development of the children in early age (Wikelund, 2005; Rinaldi \& Howe, 2012). It considered that the womb of the mother is the first institution for learning the child. The maternal style helps the child to develop the confidence level in early age. The parental style has its vital role for the development of the children (Conrede, et al., 2001; Rinaldi et al., 2012). The parental style supervises all the activities performed. Both paternal and maternal parenting help the students for the betterment of personality (Yazofol, Seyisa \& Altuna, 2011).

Baumrind (2005) and Banghdaserians (2010) suggested that authoritarian, permissive, and authoritative are the main factors of parenting. In authoritative parenting the parents provides structure and sets limits but explain reasons for punishment in an effort to encourage independence. The philosophy behind this style is that children will grow up to be emotionally secure and enjoy higher self-esteem when they learn to separate from their parents at their own pace. (Dwairy, 2010; Yazofol, Seyisa \& Altuna, 2011). The authoritative approach of parenting has been shown to lead the best outcomes in children and more secure attachment with their parents. Authoritarian Parenting do not trust their children to make a good choice. While parents with this style have high expectations and strict rules, in this style parents do not give their children much freedom to demonstrate that they can display good behavior and make good choices (Grolnick \& Pomerantz, 2009; Arnett, 2013). In permissive parenting the parents characterized by low demands with high responsiveness. Permissive parents tend to be very loving, yet provide less guidelines and rules. In this type of parenting the parents do not expect mature behavior from their children and often seem more like a friend than a parental figure (Ogunleye et al.,2013; Pauker et al., 2017). Emotional intelligence refers to the capability of a person to manage and control his emotions for performing the specific task. In educational context emotional intelligence is a skill that identify the positive emotions and understandings that contribute the academic success of the students (Cotton \& Wikelund, 2001; Pauker et al., 2017). The Goleman (2001) and Gardner (1993) theories of emotional intelligence have elicited great interest both in the academic and the non-academic world. Therapists, educators, and parents want to know what they can do to help children develop their emotional intelligence (Alegre, 2011).

\section{Problem Statement}

Parenting is the set of strategies used by parents to put their children's behavior under control which can be influenced by numerous factors including socio-economic constructs, cultural differences, personal characteristics and psychological factors. It is essential because children acquire the abilities to become responsible, caring adults of their society from the people who are most intensely involved with them. Therefore, parenting is the most important and challenging job yet it receives little support and recognition in our society.

\section{Hypothesis}

H1. There is significance relationship between authoritative style and emotional intelligence. $\mathrm{H} 2$. There is significance relationship between authoritarian style and emotional intelligence. H3. There is significance relationship between permissive style and emotional intelligence. 


\section{METHOD}

The study is descriptive in its nature. Parenting styles was independent variable whereas, emotional intelligence was dependant variable in this study. This study is quantitative based on survey method. Population was the students of public elementary schools from Guangxi, China. 239 elementary school students were the sample of the study and were selected through simple random sampling technique. Two questionnaires were used: Parental Authority Questionnaire was adopted from (Buri, 1991) with 0.89 reliability index. The dimensions comprised in this scale were authoritative, authoritarian, and permissive, it comprised on 33 items. Whereas, second emotional intelligence questionnaire was adopted from Schutte Self Report Emotional Intelligence Test (2009) with reliability index 0.87 . The dimensions comprised in this scale were appraisal of emotion, social skills, emotional utilization and optimism. It was consisted on 30items. 5 points likert scale 1 . Strongly Disagree to 5. Strongly Agree adopted for the development of scale. For assessing the reliability of scale Cronbach's Alpha Cofficient was applied that was more than 0.7 the threshold value suggested by (Nunnally, 1978). Data was entered in sheets using Statistical package for social science (SPSS ver-25) for analysis. It was analysed by using descriptive and inferential statistics Descriptive statistics (mean and standard deviation), Pearson Correlation and Multiple Regression analysis and Post HOC.

\section{RESULTS and Findings}

Table. 1. Descriptive analysis about the factors of parenting styles

\begin{tabular}{llll}
\hline Factors & N & M & SD \\
\hline Permissive parenting & 239 & 3.12 & .53 \\
Authoritarian parenting & 239 & 3.52 & .62 \\
Authoritative parenting & 239 & 3.72 & .65 \\
\hline
\end{tabular}

Overall Mean $=(M=3.45, S D=.60)$

In order to assess the level of parenting style among the elementary school students, descriptive analysis was conducted. Statistically, Mean of the constructs was ranging from $M=(3.12$ to $3.72), \mathrm{SD}=(.53$ to .65$)$ and total $(\mathrm{M}=3.45, \mathrm{SD}=.60)$. More than 3.0 mean showed that the students are satisfied about parenting styles.

Table. 2. Descriptive analysis about the factors of emotional intelligence

\begin{tabular}{llll}
\hline Factors & N & M & SD \\
\hline Appraisal of emotion & 239 & 3.52 & .62 \\
Social skills & 239 & 3.77 & .67 \\
Emotional utilization & 239 & 3.74 & .68 \\
Optimism & 239 & 3.71 & .69 \\
\hline
\end{tabular}

Overall Mean $=(M=3.68, S D=.66)$

In order to assess the level of emotional intelligence among the elementary school students, descriptive analysis was conducted. Statistically, Mean of the constructs was ranging from $\mathrm{M}=$ (3.52 to 3.77), $\mathrm{SD}=(.62$ to .69$)$ and total $(\mathrm{M}=3.68, \mathrm{SD}=.66)$. More than 3.0 mean showed that the students are satisfied about emotional intelligence

Table.3. Pearson correlation

\begin{tabular}{lccccc}
\hline Exogenous Variables & AE & SS & EU & OP & AP \\
\hline Appraisal of emotion & 1 & & & & \\
Social skills & $.468\left(^{* *}\right)$ & 1 & & & \\
Emotional utilization & $.389\left(^{*}\right)$ & $.354\left(^{*}\right)$ & 1 & & \\
Optimism & $.32\left(^{*}\right)$ & $.571\left(^{* *}\right)$ & $.443\left(^{* *}\right)$ & 1 & \\
Authoritative Parenting & $.586\left(^{* *}\right)$ & $.449\left(^{* *}\right)$ & $.533\left(^{* *}\right)$ & $.429\left(^{* *}\right)$ & 1 \\
\hline ** Correlation is significant at the 0.01 level (2-tailed).
\end{tabular}

A relationship between emotional intelligence and parental styles was found by using Pearson correlation that authoritative and appraisal of emotions has moderate relation with ( $\mathrm{r}=.586)$, authoritative and social skills has also moderate relation with $(\mathrm{r}=.449)$, authoritative and 
emotional utilization has also moderate relation with $(\mathrm{r}=.533)$, authoritative and optimism has also moderate relation with $(\mathrm{r}=.429)$.

Table. 4. Pearson correlation

\begin{tabular}{llllll}
\hline Exogenous Variables & AE & SS & EU & OP & AP \\
\hline Appraisal of emotion & 1 & & & & \\
Social skills & $.354\left(^{*}\right)$ & 1 & & & \\
Emotional utilization & $.319\left(^{*}\right)$ & $.457\left(^{* *}\right)$ & 1 & & \\
Optimism & $.428\left(^{* *}\right)$ & $.326\left(^{*}\right)$ & $.359\left(^{*}\right)$ & 1 & \\
Authoritarian Parenting & $.419\left(^{* *}\right)$ & $.389\left(^{*}\right)$ & $.324\left(^{*}\right)$ & $.392\left(^{*}\right)$ & 1 \\
\hline
\end{tabular}

** Correlation is significant at the 0.01 level (2-tailed).

A relationship between emotional intelligence and parental styles was found by using Pearson correlation that authoritarian and appraisal of emotions has moderate relation with ( $\mathrm{r}=.419)$, authoritarian and social skills has weak relation with ( $\mathrm{r}=.389)$, authoritarian and emotional utilization has also weak relation with $(\mathrm{r}=.324)$, authoritative and optimism has also weak relation with $(\mathrm{r}=.392)$.

Table. 5. Pearson correlation

\begin{tabular}{llllll}
\hline Exogenous Variables & AE & SS & EU & OP & PP \\
\hline Appraisal of emotion & 1 & & & & \\
Social skills & $.476\left(^{*}\right)$ & 1 & & & \\
Emotional utilization & $.342(*)$ & $.449\left(^{* *}\right)$ & 1 & & \\
Optimism & $.437\left(^{* *}\right)$ & $.437\left(^{* *}\right)$ & $.423\left(^{* *}\right)$ & 1 & \\
Permissive Parenting & $.525\left(^{* *}\right)$ & $.499\left(^{* *}\right)$ & $.447\left(^{* *}\right)$ & $.323\left(^{*}\right)$ & 1 \\
\hline
\end{tabular}

** Correlation is significant at the 0.01 level (2-tailed).

A relationship between emotional intelligence and parental styles was found by using Pearson correlation that permissive and appraisal of emotions has moderate relation with ( $\mathrm{r}=.525)$, permissive and social skills has also moderate relation with ( $\mathrm{r}=.499)$, permissive and emotional utilization has also moderate relation with $(\mathrm{r}=.447)$, permissive and optimism has weak relation with $(\mathrm{r}=.323)$.

Table. 6. Multiple Regressions

\begin{tabular}{llllll}
\hline Model & Parenting & Std. Error & Beta & T & p \\
\hline Emotional Intelligence & (Constant) & & & & \\
& Authoritative & .039 & .419 & 10.73 & .00 \\
& Authoritarian & .042 & .159 & 3.81 & .00 \\
& Permissive & .058 & .321 & 5.67 & .00 \\
\hline
\end{tabular}

Dependent Variable: EI, $R^{2}=.588, F=158.79$

The effect of parenting styles was found by using multiple regression that variance, $F(3,214)$ $=158.79, \mathrm{P}<.01$ explained on emotional intelligence. It found that authoritarian has statistically significant with recoded beta value ( $\beta=.159, \mathrm{P}<.05$ ), while the authoritative having the higher beta value $(\beta=.419,<.05)$ than permissive with recoded beta value $(\beta=.321, P<.05)$. $\mathrm{R}^{2}$ means there was $58 \%$ variance of parenting styles on emotional intelligence.

Table. 7. Post HOC

\begin{tabular}{|c|c|c|c|c|c|c|c|}
\hline \multicolumn{2}{|c|}{ Authoritative } & \multicolumn{2}{|c|}{ Permissive } & \multicolumn{2}{|c|}{ Authoritarian } & \multirow[t]{2}{*}{$\mathrm{G}^{*}$} & \multirow[t]{2}{*}{ Effect } \\
\hline M & SD & M & SD & M & SD & & \\
\hline 4.39 & .47 & 3.69 & .58 & & & $.00^{*}$ & Authoritative $>$ P \\
\hline 4.84 & .38 & 4.22 & .53 & $\begin{array}{l}3.29 \\
3.38\end{array}$ & $\begin{array}{l}.62 \\
.49\end{array}$ & $\begin{array}{l}.012^{*} \\
.032\end{array}$ & $\begin{array}{c}\text { Authoritative }>\text { AN } \\
\text { Permissive }>\text { AN }\end{array}$ \\
\hline
\end{tabular}

* The mean difference is significant at the .05 level.

Dependent Variable: EI 
The Post HOC was applied in order to find the significance effect of parenting styles on emotional intelligence. It was found that the authoritative style is the best style to develop the emotional intelligence of elementary school students.

\section{CONCLUSIONS and DISCUSSION}

It was concluded that the elementary school students were well aware about the parenting styles and emotional intelligence in China. Moreover, parenting styles have significant correlation with emotional intelligence. Additionally, authoritative style of parenting is the best style for the development of emotional intelligence. In spite of all the objections the permissive parenting style is the most effective for the growth of their personality traits. Previous researches emphasized that this style is consistently linked to the best outcome of the children. Therefore, authoritative parenting style is considered the best style for the development of emotional intelligence (Jisha, 2016). The study in line with previous studies that suggested the parenting plays an important role for the enhancement of ability in learning process (Mattar, 2017). Responsibilities of the parents sometime not included in formal activities that cause of unsatisfactory performance of the students. An effective parental style is a key to success for the whole educational process of the students especially at elementary level (Lekavicienea \& Antinieneb, 2016).

\section{REFERENCES}

1. Alegre, A. (2011). Parenting styles and children's emotional intelligence: What do we know? The Family Journal, 19(1), 56-62.

2. Alegre, A. (2012). The relation between the time mothers and children spent together and the children's trait emotional intelligence.Child \& Youth Care Forum, 41, 493508.doi:10.1007/s10566-012-9180-zhttps://www.infona.pl/resource/bwmeta1. element. springer-30a22796-2564-34d1-bfa7-c1cd31232df5

3. Alizadeh, S., Talib, M. B. A., Abdullah, R., \& Mansor, M. (2011). Relationship between parenting style and children's behavior problems. Asian Social Science, 7(12), 195-200.

4. Arnett, J. J. (2013). Adolescence and Emerging Adult, A Cultural Approach.

5. Arzeen, S., Hassan, B., \& Riaz, M. N. (2012). Perception of Parental Acceptance and Rejection in Emotionally Empathic and Non-Empathic Adolescents. Pakistan Journal of Social \& Clinical Psychology, 9(3).

6. Asghari, M.S \&Besharat M.A (2011) The relation of perceived parenting with integrative self-knowledge. Social and Behavioral Sciences 30 (2011) 226 - 230.

7. Banghdaserians, E. S. (2010). Authoritarian and authoritative parenting styles: A crosscultural study of Armenian Americans and European Americans' parenting styles of young children . Retrieved from ProQuest Dissertations and Theses Database. UMI No. 3412134

8. Barnhart, C. M., Raval, V. V., Jansari, A., \& Raval, P. H. (2013). Perceptions of parenting style among college students in India and the United States. Journal of Child and Family Studies, 22(5), 684-693.

9. Caruso, R.D, Mayer, J \& Salovey, P.(2010).Relation of an Ability Measure of Emotional Intelligence to Personality. Journal of personality Assessment 79(2) p,306-320 http://www. tandfonline.com/doi/abs/10.1207/ S15327752 JPA7902_12

10. Chidiebere, N. V. (2016). Parenting styles and Social Interaction Senior Secondary School Students in Imo State, Nigeria. International Educational Applied Scientific Research Journal, 1(1).

11. Conrade, G., \& Ho, R. (2001). Differential parenting styles for fathers and mothers. Australian Journal of Psychology, 53(1), 29-35.

12. Cotton, K., \& Wikelund, K.R. (2001). Parent involvement in education. http://www. nwrel.org/ scpd/sirs /3/cu6.html 
13. Dwairy, M. (2010). Parental acceptance-rejection: A fourth cross-cultural research on parenting and psychological adjustment of children. Journal of Child and Family Studies, $19,30-35$

14. El-Sheikh, M., Hinnant, J. B., Kelly, R. J., \& Erath, S. (2010). Maternal psychological control and child internalizing symptoms: Vulnerability and protective factors across bioregulatory and ecological domains. Journal of Child Psychology and Psychiatry, 51(2), 188-198.

15. Gardner, H. (1993). Multiple intelligences: the theory in practice. New York: Basic Books https://howardgardner01.files.wordpress.com/2012/06/443-davis-christodoulou seider-mi-article.pdf

16. Goleman, D. (2001). Emotional Intelligence. Bucharest: CurteaVeche

17. Grolnick, W. S., \&Pomerantz, E. M. (2009). Issues and challenges in studying parental control: Toward a new conceptualization. Society for Research in Child Development, 3(3), 165- 170.

18. Jisha K V (2016).A Study on the Relationship of Parenting Style with Emotional.Maturity of Secondary School The International Journal of Indian Psychology, 3(3) No.1, DIP: 18.01.004/20160303

19. Khajehpour,M.(2011)Relationship between emotional intelligence, parental involvement and academic performance of high school students.

20. Kordi, A., \& Baharudin, R. (2010). Parenting attitude and style and its effect on children's school achievements. International journal of psychological studies, 2(2), 217.

21. Lekavicienea,R., \&Antinieneb, D. (2016).High Emotional Intelligence: Family Psychosocial factors. Social and Behavioral Sciences. 21(7), ( 2016 ) $609-617$

22. Mattar, J.W (2017).The difference in emotional intelligence in relation to levels of maltreatment of Jordanian secondary school students.International Journal of Adolescence and Youth.1-9 http://www.tandfonline.com/ doi/citedby/ 10. 1080/02673843.2017.1292926? scroll=top\&need Access=true

23. NayerehParishani, ParisaNilforoosha. (2014). Predictive Role of Parenting Styles, Emotional Intelligence and Career Decision Making SelfEfficacy. Reef Resources Assessment and Management Technical Paper, Vol. 43, No.4, ISSN:1607-7393

24. Nunnally, (1978). Psychometric methods.

25. Ogunleye, A. J., Omirin, M. S., \&Balogun, S. K. (2013). Males, females, parenting styles, and academic performance of secondary school students in Ekiti State Nigeria: An empirical investigation. Elixir Human Res. Mgmt., 56, 13626-13629.

26. Pauker, S., Perlman, M., Prime, H., \& Jenkins, J. M. (2017). Differential parenting and children's social understanding. Social Development, 26(3), 645-657.

27. Rinaldi, C. M., \& Howe, N. (2012). Mothers' and fathers' parenting styles and associations with toddlers' externalizing, internalizing, and adaptive behaviors. Early Childhood Research Quarterly, 27(2), 266-273.

28. Rivers, J., Mullis, A. K., Fortner, L. A., \& Mullis, R. L. (2012). Relationships between parenting styles and the academic performance of adolescents. Journal of Family Social Work, 15(3), 202-216.

29. Wikelund, K. (2005). Parent involvement in education. Available at: http:/www. nwrel.org/. Accessed 03/18/ 2005

30. Williams, L. (2013). The 4 types of parenting styles. Retrieved from http://lqwilliams 2.hubpages.com/hub/ The-3-Types-of-Parenting-Styles. in Training.Training and Education in Professional Psychology.

31. Yazofol, H, Seyisa ,S., Altuna, F(2011). Emotional intelligence and self-efficacy beliefs as predictors of academic achievement among high school students. Social and Behavioral Sciences 15 (2011) 2319-2323 